THE JOURNAL OF CHEMICAL INDUSTRY, TOKYO, JAPAN.

Vol. XXIII. MAY, $1920 . \quad$ No. 267.

ABSTRACTS FROM THE ORIGINAL PAPERS.

\title{
DETECTION OF MINUTE QUANTITY OF PETROLEUM BENZINE CONTAINED IN VEGETABLE OILS.
}

\author{
By Masahiro Aida, Rigakushi.
}

[Received March 15, 1920]

Many known methods for the detection of petroleum benzine contained in vegetable oils have been studied thoroughly. They are enumerated as follows:-(I) Decrease of saponification value, acid value, specific gravity, flashing point; (2) Fractional distillation; (3) Outerbridge's method (fluorescence under the enclosed arclight or window light); (4) Extraction after saponification; (5) Ferdinand and Schulz-Kolin's method (colouration by picric acid dissolved in pure benzol free from thiophene); (6) Trichloracetic acid reaction; (7) Arragon's test (nitric acid). All these methods being proved not satisfactory for the present purpose, much efforts have been done toward the determination of the accurate method to detect the minute quantity of petroleum benzine in vegetable oils.

The author succeeded to apply Nastjukoff's formolite reaction in this detection; its procedure is as follows :-

First saponify the sample oil (50-100 grms.) contained in a stoppered flask by the gradual addition of potassium hydroxide solution in a little excess.

Warm the flask, if nec ssaly, on a water-bath using a reflux condenser provided with a long helical inner tubing and shake frequently in order to render the saponification completely. 
After the complete saponification cool the contents, add a small quantity of distilled water and some pure calcium chloride solution from the upper end of the condenser, and subject to distillation by passing the current of steam applying moderate heat to the bottom of the flask. As a recciver of the distillate choose a slender-necked flask and it is better to cool the flask with some freezing mixture.

Then take an evaporating dish, add one third quantity of $40 \%$ formaldehyde solution and rinse the innerside of the dish from time to time after addition of some quantity of the distillate followed by the several drops of concentrated sulphuric acid taken by means of a pipette. Reddish-brown film (gradually changing to dark yellow colour) or colouration on the surface of the liquid proves the presence of petroleum benzine.

Furthermore, the addition of a few drops of the distillate to pure water contained in a casserole produces a brilliant interference ring of optical waves on the surface of water, almost invisible after standing for some time and disappearing completely on heating, while in case of soja bean oil it does not change at all even by heating.

This process is the most reliable for the detection of minute quantity (even the trace) of petroleum benzine contained in vegetable oils and also can serve as its quantitative method in one sample by weighing the formolite precipitate after drying at $\mathrm{I} 1 \mathrm{O}-\mathrm{I} 15^{\circ} \mathrm{C}$. 